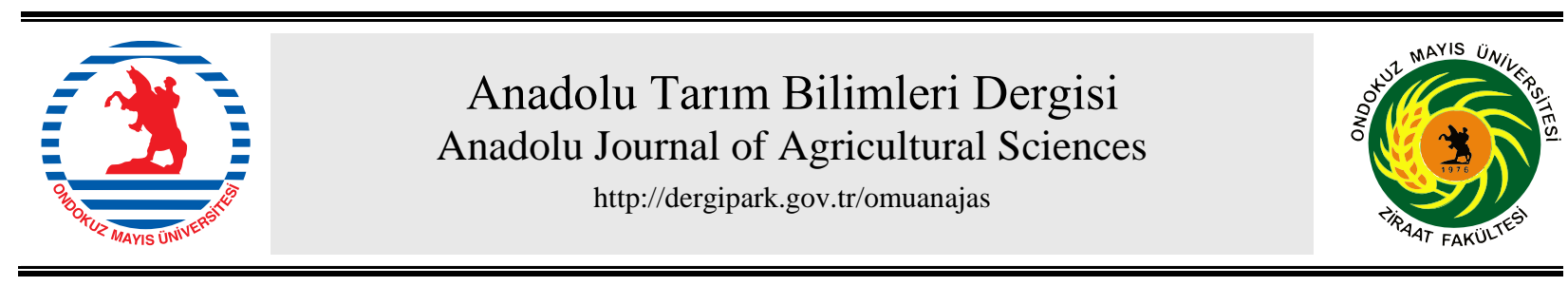

\title{
Turnayemişi (Vaccinium macrocarpon Ait.) Odun Çeliklerinde Köklenme ve Kök Gelişimi Üzerine Dışsal IBA Uygulaması ile Çelikteki Yaprakların Etkisi
}

\author{
๑Hüseyin Çelik ${ }^{\mathrm{a}^{*}}$, Fadime Neris Şenyaşa ${ }^{\mathrm{b}}$ \\ ${ }^{a}$ Ondokuz Mayıs Üniversitesi, Ziraat Fakültesi, Bahçe Bitkileri Bölümü, Samsun, Türkiye \\ ${ }^{b}$ Ondokuz Mayıs Üniversitesi, Lisansüstü Eğitim Enstitüsü, Bahçe Bitkileri Anabilim Dall, Samsun, Türkiye
}

*Sorumlu yazar/corresponding author: huscelik@omu.edu.tr

Geliş/Received 19/02/2020 Kabul/Accepted 27/05/2020

\begin{abstract}
ÖZET
Turnayemişi fonksiyonel gıda olarak kullanılan önemli bir üzümsü meyvedir. Bu çalışmada 'Pilgrim' turnayemişi çeşidinden alınan odun çelikleri kullanılmıştır. Çelikler dört yaşlı turnayemişi bitkilerine ait stolon da denilen kollar üzerindeki bir yaşlı dik sürgünlerden Mart ayı içinde alınmıştır. Yapraklı ve yapraksız olarak hazırlanan turnayemiși odun çeliklerine farklı Indole-3-butric asit (IBA) konsantrasyonları $(0,1000$ ve $2000 \mathrm{ppm})$ uygulanmıştır. Viyöllerdeki torf ortamına dikilen çelikler serada ve $24^{\circ} \mathrm{C}$ 'lik alttan 1sitmalı tavalarda mistleme sulama ile \%30 gölgeleme altında köklendirilmiştir. Turnayemişi çeliklerinde sürme ve köklenme oranı (\%), köklenme derecesi (1-9), sürgün uzunluğu $(\mathrm{cm})$, kök yaș ağırlığı $(\mathrm{g})$, toplam kök uzunluğu $(\mathrm{cm})$ ve kök çapı $(\mathrm{mm})$ saptanmıștır. En yüksek sürme (\%100) ve köklenme (\%99.00) oran1 2000 ppm IBA uygulanmış yapraklı çeliklerde olmuştur. Yapraklı çelikler tüm özellikler bakımından en yüksek sonuçları verirken en yüksek köklenme oranı 1000 ve 2000 ppm IBA uygulamasından (\%85.00) elde edilmiștir. En yüksek köklenme derecesi kontrol IBA dozunda (6.53), kök yaş ağırlı̆̆ ise 2000 ppm IBA dozunda (6.20 g) olmuştur. IBA dozu arttıkça sürme ve köklenme oranı ile kök çap1 artarken toplam kök uzunluğu azalmış, köklenme derecesi, sürgün uzunluğu ve kök yaş ağırlığı çok etkilenmemiştir. Öte yandan incelenen tüm özellikler bakımından yapraklı çelikler daha iyi sonuçlar vermiştir.
\end{abstract}

Effect of Exogenous IBA application and leaves on rooting and root growth of cranberry (Vaccinium macrocarpon Ait.) hardwood cuttings

\section{ABSTRACT}

Cranberry is an important small fruit used as functional food. In this study, hardwood cuttings collected from 'Pilgrim' cv. in March from one-year-old uprights on the runners, also called stolon, belonging to four-year-old cranberry plants. Three Indole-3-butric acid (IBA) concentrations (0, 1000 and 2000 ppm) were applied to the cuttings prepared with or without leaves. Cuttings planted in peat medium in trays and trays placed in benches with $24^{\circ} \mathrm{C}$ bottom heating and cuttings leave to rooting under $30 \%$ shading with over misting system as needed. The rooting and rooting rate (\%), rooting degree (1-9), shoot length $(\mathrm{cm})$, root fresh weight $(\mathrm{g})$, total root length $(\mathrm{cm})$ and root diameter $(\mathrm{mm})$ were determined. In leafy cuttings with 2000 ppm IBA applied, shooting (100\%) and rooting $(99.00 \%)$ were the highest. Leafy cuttings give the highest results in terms of all properties, while the highest rooting rate was obtained from 1000 and $2000 \mathrm{ppm}$ IBA application (85.00\%). The degree of rooting was the highest at the control IBA dose (6.53) and the root fresh weight at the $2000 \mathrm{ppm}$ IBA dose (6.20 g). As the dose of IBA increases, the rate of shooting and rooting and the diameter of the root increase, total root length decreased and rooting degree, shoot length and fresh root weight are not affected much. On the other hand, leafy cuttings gave higher results in terms of all the properties examined.

Anahtar Sözcükler:

Turnayemişi

Odun çeliği

Yaprak

IBA

Köklenme
Keywords:

Cranberry

Hard-wood cutting

Leaf

IBA

Rooting

(C) OMU ANAJAS 2020 


\section{Giriş}

Türkiye'nin yeni üzümsü meyvesi olan Turnayemişi yayılıc1, sürünücü ve herdemyeşil bitkilere sahiptir. Maviyemiş ve kekreyemiş gibi fundagiller familyasında yer alan turnayemişi Kuzey Amerika'daki sulak alanlarda doğal olarak yetişir ve çok yıllık bitkileri vardır. Ilıman iklimde yetișen turnayemiși üretiminin büyük bir kısmı Amerika'da Wisconsin ile Massachusetts'te yapılmaktadır. Turnayemişi çiçeği turna kuşunun baş, gerdan ve gagasına benzediği için İngilizce'de craneberry (crane=turna) ismiyle isimlendirilmiş, zamanla "cranberry" olarak kısaltılmıștır (Dana, 1990; Çelik ve İslam, 2013; Çelik ve Özgen, 2008; Çelik, 2011; Şenyaşa ve Çelik, 2019). Sağlık açısından yararlı olduğu kadar birim alandan yüksek gelir getiren bu meyve fonksiyonel gida olarak çok değerlidir (Strik ve ark., 2002; Strik ve Davenport, 2002). İki binli yıllarda Prof. Dr. Hüseyin ÇELİK tarafindan Türkiye'ye tanitılan bu üzümsü meyve "turnayemişi" olarak ülke tarımına ve literatürümüze katılmıştır. Türkiye'de asitli toprakların yer aldığı Karadeniz Bölgesi'nde kuru hasat ve Çarşamba ile Bafra ovalarındaki asitli ve sulak alanlarda ise su içinde hasadı yapılabilecek şekilde deneme çalışmaları sürdürülmektedir (Çelik ve İslam, 2013; Çelik ve Özgen, 2008; Şenyaşa ve Çelik, 2019).

Turnayemişi tohum ve vegetatif olarak çoğaltılabilmektedir. Vegetatif çoğaltmada köklü veya köksüz kol (stolon) ve dik sürgünlerden alınan çelikler kullanılmaktadır. Yeni çeşitleri elde etmek üzere turnayemişi tohumla çoğaltılabilir ancak tohumla çoğaltma fidancılıkta kullanılmamaktadır (Dana, 1990; Marcotrigiano ve Mcglew, 1991; Strik ve Poole, 2002; Trehane, 2004; Çelik ve İslam, 2013). Son y1llarda doku kültürü ile çoğaltma da kullanılmaktadır (Ropper ve Vorsa, 1997; Trehane, 2004; Çelik ve İslam, 2013; Kovr ve ark., 2019). Turnayemişinin çoğaltılmasında kullanılan çelikler iyi gelişme gösteren dik sürgünlerden alınabildiği gibi yatay kollardan da alınmaktadır. Ancak bir yaşlı dik sürgünlerden budama ile alınan çelikler daha iyi köklenmektedir (Strik ve Poole, 2002, Larson ve ark., 2002; Özgen ve Çelik, 2007; Çelik ve İslam, 2013). Turnayemişinin tohum ile çoğaltılmadığını belirten Grant (2018), 3-4 yaprak içeren ve maksimum $20 \mathrm{~cm}$ uzunluğunda olan çelikleri besin maddesince zengin kum+kompost ortamına dikerek yüksek başarı elde etmiştir. Strik ve ark. (2002), kuru hasat veya su içinde hasat sırasında meyveleri toplayan makinelerin aynı zamanda bitkilerde de budama yaptığını ve budama artıklarının çelik olarak kullanılabileceğini ifade etmektedir. Aynı araştırıcı, doku kültüründe üretilerek saksıda büyütülen turnayemişi fidanları üzerine çalıştıklarını da belirtmektedir. Turnayemişi yatay sürgünlerinin (stolon) bir mevsim boyunca 60-90 cm kadar uzadıklarını belirten Dana (1990), hasat sırasında bu sürgünler üzerinde bir sonraki yıl oluşan dik ve kısa sürgünlerin çelik almak üzere kullanılabileceğini belirtmektedir. Turnayemişi çelikleri dikilen ortamların sürekli nemli olması gerektiğini belirten Dana (1990), köklenmenin 2-3 hafta içinde başlayabileceğini tespit etmiştir. Trehane (2004), ticari turnayemişi üreticilerinin yeni plantasyonlarda uzun çelikler kullandığını ve ilkbaharda tavalardan toplanan çeliklerin yeni tavalara ekildiğini belirtmektedir. Turnayemişi çeliklerinin kolay köklendiğini belirten araştırıcı mistleme ve alttan 1sitmalı ortamlarda $8-10 \mathrm{~cm}$ uzunluğundaki çeliklerde uçtan itibaren 6-8 yaprak bırakılabileceğini saptamıştır. Trehane (2004), $5 \mathrm{~cm}$ derinliğindeki küçük saksılardaki torf ve kum (1:1) ortamına dikilen çeliklerin köklenebildiğini, mistleme sisteminin köklenmeyi artırdığını, torf bloklarına dikilen çeliklerdeki köklenme oranının yüksek olduğunu ve üç hafta içinde köklenmenin başladığını saptamıştır. Bitkisel materyalin az olduğu yerlerde çeliklerin köklendirilmesi sonucu elde edilen tüplü fidanlar ile turnayemişi bahçelerinin kurulumunun daha ucuz olduğunu belirten Scorza ve Welker (1988), çeliklerin kol veya kısa dik sürgünlerden alınabileceğini belirtmiştir. Turnayemişlerinde vegetatif gelişmenin kontrol altına alınması için budama yapılması gerektiğini belirten Strik ve Poole (2002), budama ile alınan çeliklerin çoğaltmada kullanılabileceğini ve budanan dik sürgünlerde yan dal sayısının arttığını ve verimin de yükseldiğini tespit etmişlerdir. Turnayemişlerinin ilkbaharda alınacak sert odun çelikleri ile çoğaltıldığını belirten Gough (2008), köklendirme yastıklarına dikilen çeliklerin köklenme başarısının nispeten yüksek olduğunu tespit etmiştir. Turnayemişi gibi Vaccinium cinsi içinde yer alan kekreyemişin sert veya yumuşak odun çelikleri ile çoğaltılabileceğini saptayan St. Pierre (1996), 6000 ppm IBA ile $\% 85$ başarı elde etmiştir. Sürgün uçlarından hazırladığı kekreyemiş çeliklerine IBA uygulayan Martinussen ve ark. (2006), torf+perlit ortamında ve kontrol çeliklerinde \%66 köklenme başarısı elde ettiğini ve ilkbahar-yaz aylarında alınan çeliklerin sonbahar-kış ayı çeliklerine göre daha iyi köklendiğini bildirmiştir. Magnitskiy ve ark. (2011) ise Vaccinium floribundum sürgün uçlarından aldığı yarı-odun çeliklerine 400 ppm NAA ile \%47 köklenme başarısı elde etmiştir. Alaska'da yetişen Vaccinium uliginosum'u sert ve yumuşak odun çelikleri ile çoğaltan Holloway ve Zasada (1979), perlit ortamında daha yüksek köklenme elde ederken yumuşak odun çeliklerinin köklenmediğini saptamıştır. Turnayemişi çeliklerinin yatay veya dikey olarak kum ortamına dikilebileceğini belirten Roper (1995), 2-3 hafta içinde yeni kök ve sürgün gelişiminin başladığını ancak köklü çeliklerin başlangıçta zayıf geliştiğini saptamıştır. Turnayemişi çeliklerindeki köklenme, kök gelişimi, büyüme ve gelişme oranı ortamdaki su miktarı ile çeşitlere göre de değişebilmektedir (Baumann ve ark., 2005). Maviyemişlerden aldığı mini çeliklere IBA uygulayan ve köklenme ortamlarını araştıran Colombo ve ark. (2018), IBA'nın köklenmeyi etkilemediği ancak çelik alma zamanlarına göre köklenme başarısının \%55-84 
arasında olduğunu saptamıştır. Çelik ve Ateş (2009) ise maviyemiş mini çeliklerinde 2000 ppm IBA'nın köklenmeyi artırdığını saptamıştır. St. Pierre (1996), Frenk ve Bektaşiüzümlerinde sert odun çeliklerinin 800 ppm, yumuşak odun çeliklerinin ise 400 ppm IBA'da iyi köklendiğini saptamıştır. Maviyemiş çeliklerindeki köklenmenin çeşit ve IBA dozlarına göre değiştiğini belirten Çelik ve Odabaş (2009) gerçek köklenme oranının \%57.76-83.23 arasında değiștiğini ve geliştirilen model ile bu oranın tahmin edilebileceğini tespit etmişlerdir. Turnayemişi çeliklerinin köklenmesi ve bitkide büyüme üzerine çelik büyüklüğü (Welker ve Vass, 1983), köklenme ortamı (Chong, 1999), ortamdaki mikoriza popülasyonu (Szwonek ve ark., 2016) ile çelik tipi ve turnayemişi çeşitlerinin (Baumann ve ark., 2005) etkili olduğu bilinmektedir. Turnayemişi ile aynı cins içinde yer alan kekreyemişte ise çelik alma zamanı ile köklenme ortamı ve çevre şartları (Gustavson, 1999), çoğaltmada kullanılan bitki parçası (çelik, mikro parça vb.) (Debnath ve ark., 2012), çoğaltma metodu (Gustavsson ve Stanys, 2000) ve IBA'nın (Debnath, 2006) köklenmeyi etkilediği tespit edilmiştir. Benzer bir şekilde turnayemişi ile Vaccinium cinsi içinde yer alan maviyemişlerde ise oksin tipi (IBA), çelik tipi ve çoğaltma materyalinin genetik stabilitesi (Pacholczak ve Nowakowska, 2015; Fischer ve ark., 2016; Nowakowska ve Pacholczak, 2017), çeşit (Fischer ve ark., 2008 a ve b), çoğaltmada kullanılan metot (Jamieson ve Nickerson, 2003; Litwinczuk ve ark., 2006; Miller ve ark., 2006; Albert ve ark., 2009; Marino ve ark., 2014), büyümeyi düzenleyiciler ve kök bölgesi sicakllğı (Lee ve Lee, 2009), çeliğin sürgün üzerindeki yeri ve çelik büyüklüğü (Pelizza ve ark., 2011), köklendirmede kullanılan kaplar, ortamlar, IBA dozu ve çelik büyüklüğü (Nascimento ve ark., 2011; Ristow ve ark., 2012), IBA, kök bölgesi sıcaklı̆̆ 1 ve çeliğin alındığı mevsim (Marangon ve Biasi, 2013), çelik tipi, büyümeyi düzenleyici ve çeşit (Fischer ve ark., 2008 a?? b??), çelik tipi, köklenme ortamı (Çelik, 2007; Çelik, 2016), alttan ısıtma sıcaklığı (Çelik, 2006), çelik alma zamanı ve IBA dozu (Çelik, 2017), çelikteki yapraklar ve bazaldaki kesim şekli (Çelik ve Ateş, 2009) ile diğer birçok iç ve dış faktör etki edebilmektedir (Couvillon, 1988; Karabulut ve Çelik, 2019).

Türkiye'nin yeni meyvesi olan turnayemişinin çoğaltılması üzerine Türkiye'de ilk kez yapılan bu çalışmada 'Pilgrim' turnayemişine ait bir yaşlı dik sürgünlerden alınan sert odun çeliklerinde büyüme, gelişme, köklenme ve kök kalitesi üzerine IBA dozları ile çelikteki yaprakların etkisi tespit edilmiştir.

\section{Materyal ve Yöntem}

Araştırmada Türkiye'de ilk kez tescil edilmiş olan 'Pilgrim' turnayemişi çeşidine ait sert odun çelikleri materyal olarak kullanılmıştır (Şekil 1). Mart ayı içinde bir yaşlı dik sürgünlerden alınan odun çelikleri yapraklı (5-7 adet) ve yapraksız olarak 8-10 $\mathrm{cm}$ boyunda hazırlanarak IBA $(0,1000$ ve 2000 ppm) ile muamele edilmiştir. IBA uygulanmış çelikler 32'lik viyöllerdeki $(51 \times 32 \mathrm{~cm}) 7 \mathrm{~cm}$ derinliğe sahip hücrelere doldurulan asit $(\mathrm{pH}=4.5-5.5)$ ayarlı torf ortamına dikilerek cam serada mistleme sulama altında ve $24^{\circ} \mathrm{C}$ 'lik alttan isitma sıcaklığına sahip tavalarda köklendirilmiştir (Ruter, 2015). Denemeden elde edilen köklü çeliklerde sürme ve köklenme oranı (\%), köklenme derecesi (1-9), sürgün uzunluğu $(\mathrm{cm})$, kök yaş ağırlığı (g.), toplam kök uzunluğu $(\mathrm{cm})$ ve kök çapı $(\mathrm{mm})$ tespit edilmiştir. Köklenme derecesi Çelik (2007, 2012, 2016 ve 2017) tarafindan da kullanılan skalaya göre saptanmıştır. Kökler akar su altında yıkandıktan sonra toplam kök uzunluğu ve kök çapı WinRHIZO ${ }^{\mathrm{TM}}$ Dijital Kök Analiz Cihazı ve yazılımı ile (Regent Instruments Inc., Quebec, Canada) saptanmıştır (Parnaro ve ark., 2017; Anon., 2019). Deneme 4 tekerrürlü ve her tekerrürde 25 çelik olacak şekilde tesadüf blokları deneme desenine göre kurulmuş, istatistiki analizler SPSS programında ANOVA kullanılarak yapılmış olup ortalamalar arasındaki farklılıklar DUNCAN çoklu karşılaştırma testi kullanılarak harflendirilmiştir. Denemedeki \%değerlere ise Açı Transformasyonu $(\arcsin \sqrt{ } \mathrm{x})$ uygulanarak istatistiki analizler bu transforme edilmiş rakamlar üzerinden yapılmıştır.

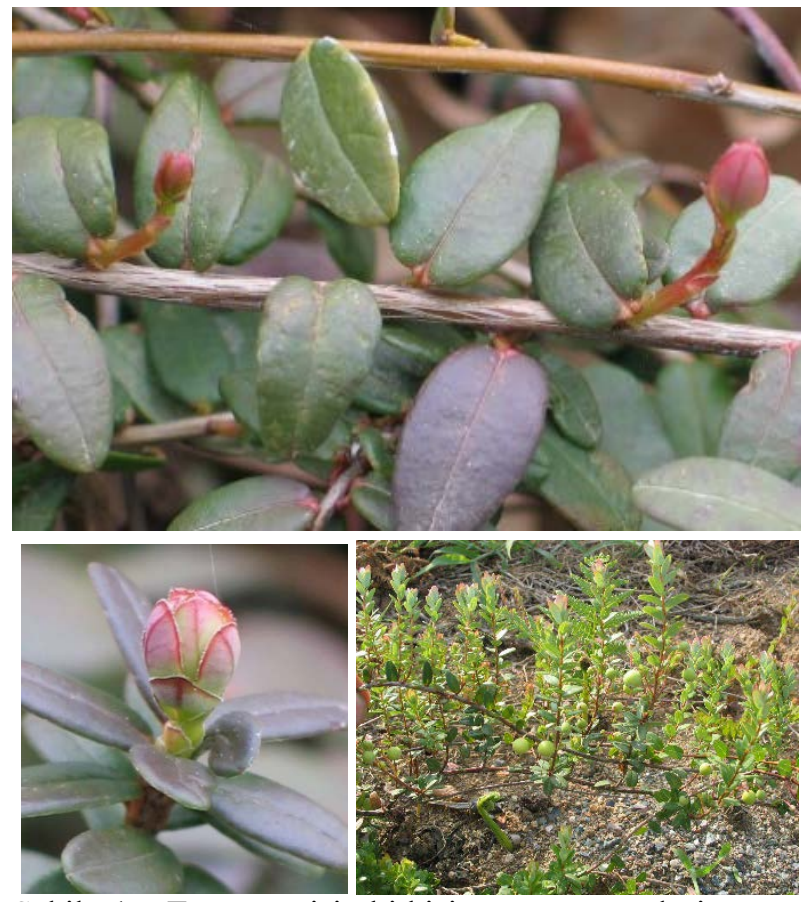

Şekil 1. Turnayemişi bitkisi, yatay gövdesi, tepe tomurcuğu, meyveli ve meyvesiz dik sürgünleri

Figure 1. Cranberry vine, horizontal runners (stolon), terminal bud and uprights with or without fruit 


\section{Bulgular ve Tartışma}

'Pilgrim' turnayemişi çeşidinin bir yaşlı dik sürgünlerinden yapraklı ve yapraksız olarak alınan odun çeliklerindeki sürme ve köklenme oranı ile köklenme derecesi üzerine IBA dozlarının etkilerine ait bulgular Çizelge 1'de verilmiştir. Çizelgeden de görülebileceği gibi çelik tipi ve IBA doz interaksiyonu ortalamaları arasında çeliklerde sürme oranı, köklenme oranı ve köklenme derecesi bakımından istatistiki olarak çok önemli farklılıklar ortaya çıktığı saptanmıştır. Yapraklı olarak alınan ve 2000 ppm IBA uygulanan turnayemişi odun çeliklerindeki sürme oranı $\% 100.00$ ile en yüksek seviyeye ulaşırken yapraksız çeliklerdeki sürme oranı kontrol uygulamsında $\% 80.00$ iken diğer dozlarda \%89.00 ile yapraklı çeliklere göre daha düşük olmuştur. IBA uygulaması yapılmayan yapraklı turnayemişi çeliklerinde \%97.00'lik sürme elde edilmesi ve IBA uygulanmış yapraklı çeliklerdeki sürme oranları ile aynı istatistiki grupta olduğu için sürme bakımından IBA uygulamalarının yapraklı çeliklerde etkisiz ancak yapraksız çeliklerde daha etkili olduğu saptanmıştır. Öte yandan köklenme oranı bakımından yapraklı ve 2000 ppm IBA dozu \%99.00 ile en yüksek orana ulaşırken yapraksız olarak alınan çeliklerdeki IBA uygulamasının etkisi çok daha belirgin olmuş ve 1000 ppm IBA dozu \%74.00 köklenme başarısı göstermiştir. Köklenme derecesi bakımından çelik tipi ve IBA dozları arasında istatistiki olarak farklılık olmamasına rağmen IBA uygulanmamış kontrol dozundaki yapraksız veya yapraklı çeliklerdeki köklenme derecesi sırasıyla 6.58 ve 6.48 ile kuvvetli kök oluştururken IBA uygulanmış çeliklerdeki köklenme derecesi daha düşük seviyede kaldığ 1 tespit edilmiştir. Nitekim çelikte bırakılan yaprakların köklenmeyi olumlu olarak etkilediği Hartmann ve ark. (2014) ile Çelik ve Ateş (2009) tarafından da belirtilmektedir. Ayrıca, çelik tipi (Baumann ve ark., 2005), büyümeyi düzenleyiciler ve kök bölgesi sıcaklığına (Lee ve Lee, 2009) ilaveten büyümeyi düzenleyici oksinler (IBA) ve çeliğin alındığ mevsim (Marangon ve Biasi, 2013), çelik tipi, çeşit (Çelik, 2007; Fischer ve ark., 2008 a ve b; Çelik, 2016) ile çelikteki yapraklar da (Çelik ve Ateş, 2009) çeliklerdeki köklenme oranı ve kök gelişimi üzerine etki edebilmektedir. Denemizdeki sürme ve köklenme oranı bakımından yapraklı çeliklerin çok daha yüksek sonuçlara ulaşması ve IBA konsantrasyonu arttıkça sürme ve köklenme oranlarının artması literatürlerdeki bulgulara paralellik göstermiştir (Şekil 2 ve 3). Çünkü yaprakların varlığı ve karbonhidrat mekanizması gerek sürme gerekse köklenme oranlarına olumlu katk1 sağlayabilmektedir (Hagidimitriou ve Roper, 1994). Turnayemişi dik sürgünlerindeki karbonhidrat miktarının gövde ve köklerdekinden daha yüksek olduğu da Roper ve Vorsa (1997) tarafindan bildirilmektedir. Ayrıca yapraklar tarafından üretilen karbonhidratlar çelikteki köklenmeyi teşvik edebilmektedir (Varshney ve Anis, 2014). Köklenme derecesi bakımından gerek çelik tipi gerekse IBA dozları arasında istatistiki olarak farklılık tespit edilmemiş olmasına rağmen yapraklı çeliklerdeki köklenme derecesinin (6.33) daha yüksek olduğu ve IBA dozu arttıkça köklenme derecesinin azaldığ saptanmıştır (Şekil 2 ve 3). Bu durum çelikteki yaprakların kök çapı, uzunluğu ve sayısına olumlu etki ettiği ancak IBA dozu arttıkça bu özelliklere olan etkinin azaldığını göstermektedir. Nitekim oksinlerin köklenme oranını artırarak kök gelişimine olumsuz etkide bulunduğu maviyemişler üzerine çalışan Çelik ve Ateş (2009) tarafindan da saptanmıştır. Bu durum kök bölgesindeki sıcaklığa da bağlıdır (Ruter, 2015). Ayrıca, Hartmann ve ark. (2014) IBA'nın köklenme ve kök sayısı üzerine olumlu etkisinin olduğunu da belirtmektedir. Araştırıcılar genç dokularda IBA uygulamasından sonra IAA konsantrasyonunun arttığını ancak yaşlı ve odunlaşmış dokularda ise IBA miktarının zaten yüksek olduğunu ve odun çeliklerinde IBA ve IAA'nın beraber kullanılmasına gerek olmadığını da ifade etmektedirler.

Çizelge 1. Turnayemişi odun çeliklerinde sürme ve köklenme oranı (\%) ile köklenme derecesinin (1-9) çelik tipi ve IBA dozlarına göre değişimi

Table 1. Changing of the rate of shooting and rooting (\%) and rooting degree (1-9) in cranberry hardwood cuttings according to cutting type and IBA doses

\begin{tabular}{ccrcc}
\hline Çelik Tipi & $\begin{array}{c}\text { IBA } \\
\text { Dozu } \\
(\mathrm{ppm})\end{array}$ & $\begin{array}{c}\text { Sürme } \\
\text { Oranı (\%) }\end{array}$ & $\begin{array}{c}\text { Köklenme } \\
\text { Oranı (\%) }\end{array}$ & $\begin{array}{c}\text { Köklenme } \\
\text { Derecesi } \\
(1-9)\end{array}$ \\
\hline Yapraklı & 0 & $97.00 \mathrm{a}$ & $91.00 \mathrm{a}$ & 6.48 \\
& 1000 & $98.00 \mathrm{a}$ & $96.00 \mathrm{a}$ & 6.27 \\
& 2000 & $100.00 \mathrm{a}$ & $99.00 \mathrm{a}$ & 6.24 \\
\hline Yapraksız & 0 & $80.00 \mathrm{c}$ & $48.25 \mathrm{c}$ & 6.58 \\
& 1000 & $89.00 \mathrm{~b}$ & $74.00 \mathrm{~b}$ & 6.01 \\
& 2000 & $89.00 \mathrm{~b}$ & $71.00 \mathrm{~b}$ & 6.02 \\
\hline
\end{tabular}

Sütundaki ortalamalar arasındaki farkllık \%0.01 seviyesinde önemlidir.Köklenme derecesi 1: yok, 3: zaylf, 5: orta, 7: kuvvetli, 9:çok kuvvetli (Çelik, 2007, 2012, 2016 ve 2017)

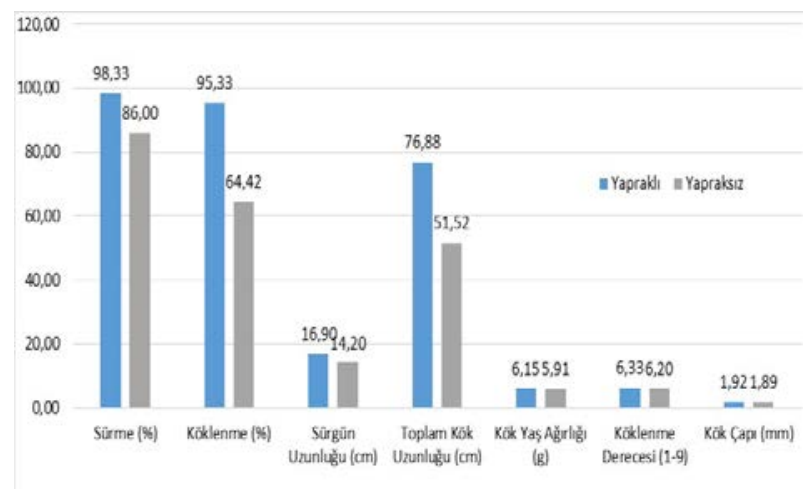

Şekil 2. Turnayemişi odun çeliklerindeki yaprak varlığının sürme, köklenme ve diğer özellikler üzerine etkisi

Figure 2. The effect of the presence of leaves in rooting, shooting and other properties of cranberry hardwood cuttings 


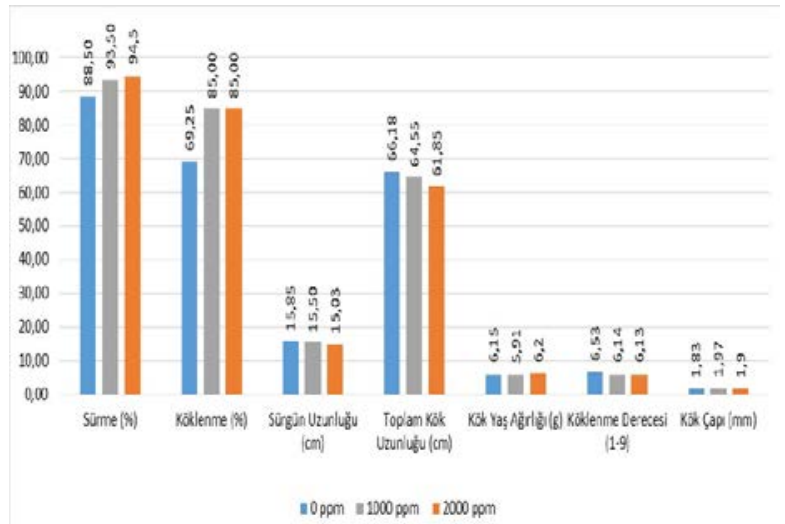

Şekil 3. Turnayemişi odun çeliklerinde IBA dozlarının köklenme ve sürme ile diğer özellikler üzerine etkileri Figure 3. Effects of IBA doses on rooting, shooting and other properties in cranberry hardwood cuttings

Denemede kullanılan 'Pilgrim' turnayemişi çeşidinin bir yaşlı dik sürgünlerinden alınan odun çeliklerinde sürgün uzunluğu, toplam kök uzunluğu, kök yaş ağırlığı ve kök çapı üzerine çelik tipi ile IBA uygulamalarının etkileri Çizelge 2'de verilmiştir. Çizelge 2'den de görülebileceği gibi çelik tipi x IBA dozları interaksiyonları bakımından sürgün ve kök özellikleri arasında çok önemli farklılıklar olduğu saptanmıştır. Nitekim IBA uygulanmamış ancak yapraklı olan çeliklerdeki sürgün uzunluğu $17.77 \mathrm{~cm}$ ile en fazla iken yapraksız çeliklerdeki azalma önemsiz olmuş ve yapraksız çeliklerde IBA dozu arttıkça sürgün uzunluğunu kontrole göre artırdığ 1 ancak bu artışın istatistiki olarak önemsiz olduğu ortaya konulmuştur (Çizelge 2). Yapraklı çeliklerde ise IBA dozu arttıkça sürgün uzunluğunun kontrole göre azaldığı tespit edilmiştir (Çizelge 2). Ancak, yapraklı çeliklerdeki sürgün uzunluğunun $(16.90 \mathrm{~cm})$ yapraksız çeliklerden $(14.20 \mathrm{~cm})$ daha fazla olduğu da tespit edilmiştir (Şekil 2). Yapraklı çeliklerdeki toplam kök uzunluğu (76.88 $\mathrm{cm})$, kök yaş ağırlığı (6.15 g), köklenme derecesi (6.33) ve kök çapının $(1.92 \mathrm{~mm})$ da yapraksız çeliklerden daha yüksek olduğu ortaya konulmuştur (Şekil 2). İstatistiki olarak önemsiz olsa da IBA konsantrasyonu arttıkça sürgün uzunluğunun azaldığı ve IBA uygulanmayan kontrol çeliklerindeki sürgün uzunluğunun $15.85 \mathrm{~cm}$ ile en yüksek olduğu tespit edilmiştir (Şekil 3). Ayrıca IBA dozu arttıkça toplam kök uzunluğu, kök yaş ağırlığı ile köklenme derecesinin de azaldığ 1 ve kontrol uygulamasinın sirasiyla $66.18 \mathrm{~cm}, 6.15 \mathrm{~g}$ ve 6.53 değerleri ile en yüksek değerde olduğu saptanmıştır. Kök çap1 ise 1000 ppm IBA dozunda $1.97 \mathrm{~mm}$ ile kontrole göre daha yüksek iken 2000 ppm dozunda düşme gösterse de $1.90 \mathrm{~mm}$ ile kontrolden daha yüksek olmuştur (Şekil 3). Nitekim Gough (2008) turnayemişini ilkbaharda aldığı sert odun çelikleri ile çoğaltarak \%84.50 köklenme başarısı sağlarken çalışmamızda yapraklı çeliklere 2000 ppm IBA uygulayarak bu oran \%99'a çıkmıştır. Öte yandan turnayemişi ile aynı cins içinde yer alan kekreyemişlerde ise sert odun çelikleri ve 6000 ppm IBA kullanan St. Pierre (1996) \%85.00 köklenme başarısına ulaşabilmiştir. Bu sonuçlar kolay köklendiği belirtilen Turnayemişlerinde IBA uygulamasının köklenme oranını yükselttiğini ortaya koymuştur. Ayrıca köklenme ortamının da başarıyı etkilediğini belirten Martinussen ve ark. (2006), kekreyemiş sürgün uçlarından aldığı yarı-odun çeliklerinde IBA ve torf+perlit ortamında \%66.00 köklenme başarısının yanında çelik alma zamanının da başarıda etkili olduğu ve ilkbahar-yaz aylarında alınan çeliklerin sonbahar-kış ayı çeliklerine göre daha iyi köklendiğini saptamıştır. Benzer şekilde kolay köklenen bazı maviyemiş çeşitlerinde IBA uygulaması ile farklı zamanlarda alınan çeliklerde köklenme oranının \%55-84 arasında olduğunu Colombo ve ark. (2018) tarafindan da saptanmıştır. Köklenme başarısı çelik tipi ve çelik alma zamanının yanında IBA dozuna da bağlı olduğu (Holloway ve Zasada, 1979), maviyemiş mini çeliklerinde 2000 ppm IBA'nın köklenmeyi artırdığı (Çelik, 2016), maviyemiş yumuşak odun çeliklerinde gerçek köklenme oranının \%57.76-83.23 arasında değiştiği (Çelik ve Odabaş, 2009), turnayemişi çeliklerinin büyüklüğü (Welker ve Vass, 1983) ve çeşitlerin de etkili olduğu bilinmektedir (Baumann ve ark., 2005). Öte yandan maviyemişlerde çelik tipi ile köklenme ortamının (Çelik, 2007; Çelik, 2016) yanında alttan 1sıtma sıcaklığı (Çelik, 2006) ve çelik alma zamanı ile IBA dozlarının (Çelik, 2017) ve özellikle de çelikteki yaprakların (Çelik ve Ateş, 2009; Karabulut ve Çelik, 2019) köklenme oranı üzerine etkili olduğu araştırıcılar tarafindan saptanmıştır. $\mathrm{Bu}$ durum Hartmann ve ark. (2014) tarafından da bildirilmiştir. Çalışmamızdaki sonuçlara göre yapraklı çeliklerdeki başarının yapraksızlara göre daha yüksek olması önceki çalışma sonuçlarıyla paralellik göstermektedir.

Çizelge 2. Turnayemişi odun çeliklerinde sürgün uzunluğu $(\mathrm{cm})$, toplam kök uzunluğu $(\mathrm{cm})$, kök yaş ağırlığı (g) ve kök çapının (mm) çelik tipi ve IBA dozlarına göre değişimi

Table 2. Changing of the shoot length $(\mathrm{cm})$, total root length $(\mathrm{cm})$, root fresh weight $(\mathrm{g})$ and root diameter (mm) in cranberry hardwood cuttings according to cutting type and IBA doses

\begin{tabular}{cccccc}
$\begin{array}{c}\text { Çelik } \\
\text { Tipi }\end{array}$ & $\begin{array}{c}\text { IBA } \\
\text { Dou } \\
(\mathrm{ppm})\end{array}$ & $\begin{array}{c}\text { Sürgün } \\
\text { Uzunluğu } \\
(\mathrm{cm})\end{array}$ & $\begin{array}{c}\text { Toplam } \\
\text { Kök } \\
\text { Uzunluğ }^{1}\end{array}$ & $\begin{array}{c}\text { Kök } \\
\text { Yaş } \\
\text { Ağı̆lığ } \\
(\mathrm{g})\end{array}$ & $\begin{array}{c}\text { Kök } \\
\text { Cap1 } \\
(\mathrm{mm})^{1}\end{array}$ \\
\hline Yapraklı & 0 & $17.77 \mathrm{a}^{*}$ & $83.82 \mathrm{a}$ & $7.31 \mathrm{a}$ & $1.94 \mathrm{~b}$ \\
& 1000 & $16.85 \mathrm{ab}$ & $74.29 \mathrm{~b}$ & $5.91 \mathrm{~b}$ & $1.91 \mathrm{~b}$ \\
& 2000 & $16.07 \mathrm{~b}$ & $72.52 \mathrm{~b}$ & $7.83 \mathrm{a}$ & $1.90 \mathrm{~b}$ \\
Yapraks1z & 0 & $13.92 \mathrm{c}$ & $48.54 \mathrm{c}$ & $4.99 \mathrm{~b}$ & $1.72 \mathrm{c}$ \\
& 1000 & $14.15 \mathrm{c}$ & $54.80 \mathrm{c}$ & $5.91 \mathrm{~b}$ & $2.04 \mathrm{a}$ \\
& 2000 & $14.00 \mathrm{c}$ & $51.19 \mathrm{c}$ & $4.57 \mathrm{c}$ & $1.90 \mathrm{~b}$ \\
\hline
\end{tabular}

*Sütundaki ortalamalar arasındaki farklılık \%0.01 seviyesinde önemlidir.

${ }^{1}$ WinRHIZO Dijital Kök Analiz Cihazl ve yazılımı (Regent Instruments Inc., Quebec, Canada) ile saptanmıştır (Parnaro ve ark., 2017; Anon., 2019). 


\section{Sonuç}

Turnayemişi Türkiye'deki asitli alanlarda yetiştirilebilecek alternatif ve fonksiyonel gida olarak kullanılabilen bir meyve türüdür. Turnayemişi bahçelerinin tesisinde gerekli olan fidanların üretilmesinde kullanılan sert odun çeliklerinin köklenmesi üzerine IBA dozu ile çelikteki yaprakların etkisinin araştırıldığı bu çalışmada, yapraklı olarak alınan ve $2000 \mathrm{ppm}$ IBA uygulanan sert odun çeliklerindeki köklenme \%99.00'a kadar yükseldiği tespit edilmiştir. IBA dozu arttıkça sürme ve köklenme oranı ile kök çap1 ve kök yaş ağırlığı artarken sürgün uzunluğu, toplam kök uzunluğu ve köklenme derecesinin azaldığı tespit edilmiştir. Bu durum IBA uygulaması ile başarının yükseldiğini ve literatüre göre çok daha yüksek köklenme elde edilebileceğini göstermektedir. Öte yandan yapraklı olarak hazırlanan sert odun çeliklerinden elde edilen sonuçların incelenen tüm özellikler bakımından yapraksız çeliklere göre daha yüksek olduğu da tespit edilmiştir. Dolayısıyla turnayemişinden Mart ayı içinde yapraklı olarak alınacak olan sert odun çeliklerine 2000 ppm IBA uygulandığında başarı en yüksek olacaktır. Böylece Türkiye'de tescil edilmiş olan 'Pilgrim' turnayemişi çeşidine ait fidanlar tüplü olarak üretilebilecek ve kısa sürede yeni bahçeler tesis edilebilecektir.

\section{Teşekkür}

$\mathrm{Bu}$ çalışmaya maddi destek veren Ondokuz Mayıs Üniversitesi Rektörlüğü Proje Yönetim Ofisine (BAPPYO.ZRT.1904.19.004) teşekkür ederiz.

\section{Kaynaklar}

Albert, T., Starast, M., Kalp, K., Kaldmae, H., Vool, E., Paal, T., 2009. The influence of propagation method on growth of the half-highbush blueberry 'Northblue'. Acta Horticulturae, 812: 141-145.

Anonymous, 2019. WinRHIZO ${ }^{\mathrm{TM}}$ Product Family For Root Image Analysis and More. Regent Ins. 8p.

Baumann, D.L., Workmaster B.A., Kosola, K.R., 2005. 'Ben Lear' and 'Stevens' cranberry root and shoot growth in response to soil water potantia. Hortscience, 40(3): 795-798.

Chong, C., 1999. Rooting of decidious woody stem cuttings in peat-and perlite-amended MSW compost media. Compost Sci. And Util., 7(4): 6-14.

Colombo, R.C., Carvalho, D.U., Cruz, M.A., Roberto, S.R., 2018. Blueberry propagation by minicuttings in response to substrate and indolebutryic acid application methods. J. of Agric. Sci. 10(9): 450458. DOI: $10.5539 /$ jas.v10n9p450

Couvillon, G.A., 1988. Rooting responses to different treatments. Acta Horticulturae, 227(1): 187-196.

Çelik, H., 2006. Kuzey orijinli yüksek çalı maviyemiş yumuşak odun çeliklerinde köklenme üzerine alttan 1sıtma sicaklığının etkisi. II. Ulusal Üzümsü Meyveler Sempozyumu, 14-16 Eylül, Tokat, 129$135 \mathrm{~s}$.

Çelik, H., 2007. Northland Kuzey Orijinli Yüksek Çalı Maviyemiş (Vaccinium corymbosum L.) Yeşil Çeliklerinin Köklenmesi Üzerine Farklı Ortamların Etkisi. V. Ulusal Bahçe Bitkileri Kongresi, 4-7 Eylül, Erzurum, Cilt 1: Meyvecilik, 37-41.

Çelik, H., 2011. Samsun için yeni ve popüler üzümsü meyveler: Maviyemiş ve Turnayemişi. Samsun Sempozyumu, 13-16 Ekim 2011, Bildiriler Kitab1, Cilt: 3, 149-158.

Çelik, H., 2012. Yüksek Boylu Maviyemiş Çeşitlerinde Köklenme Üzerine Çelik Tipi, Çelik Alma Zamanı ve Köklenme Ortamının Etkisi. IV. Ulusal Üzümsü Meyveler Semp. 3-5 Ekim, Akdeniz Üniv., Antalya. Bildiriler Kitabı: 324-335.

Çelik, H., 2016. Yüksek boylu maviyemiş (Vaccinium corymbosum L.) çeşitlerinden alınan yapraklı yumuşak odun mikro çeliklerde köklenme üzerine ortamların etkisi. Bahçe, 45(1): 1-6

Çelik, H., 2017. Yüksek boylu maviyemiş çeşitlerinden alınan yapraklı yarı odunsu çeliklerde köklenme üzerine çelik alma zamanı ve IBA uygulamalarının etkisi. BAHÇE, 46 (Özel Sayı 1): 63-72.

Çelik, H., Ateş, S., 2009. Maviyemiş (Vaccinium corymbosum L.) yumuşak odun çeliklerinde yaprak miktarı ve bazaldaki kesim yerinin köklenme üzerine etkileri. III. Ulusal Üzümsü Meyveler Sempozyumu, 10-12 Haziran 2009, Kahramanmaraş 139-146.

Çelik, H., İslam, A., 2013. Turnayemişi. Üzümsü Meyveler, 7. Bölüm, (Editör. Y.S. Ağaoğlu, R. Gerçekçioğlu), 333-377p. Tomurcukbağ Ltd. Şti., Eğitim Yay. No: 1, Ankara.

Çelik, H., Odabaş, M.S., 2009. Mathematical Modeling of the Indole-3-butyric acid applications on Rooting of Northern Highbush Blueberry (Vaccinium corymbosum L.) Softwood-cuttings. Acta Physiologiae Plantarum 31(2): 295-299. DOI: 10.1007/s11738-008-0232-9

Çelik, H., Özgen, M., 2008. Karadeniz Bölgesindeki asitli ve sulak alanlar için yeni bir meyve türü, turnayemişi. HASAD, Aylık Tarım Dergisi, Bitkisel Üretim, 23(273): 75-80p. ve 23(274): 52-57p.

Dana, M.N., 1990. Cranberry management. In: Small Fruit Crop Management (Eds: Galleta, G.J. and Himelrick, D.G.). Prentice Hall Inc. Englewood Cliffs, New Jersey: 334-362p

Debnath, S.C., Vyas, P., Igamberdiev, A.U., 2012. Characteristics of lingonberry plants propagated by in vitro and ex vitro propagation methods. Acta Hort. $\quad$ 926: 259-263.

DOI: 10.17660/ActaHortic.2012.926.35

Debnatth, S.C., 2006. Influence of propagation method and indole-3-burtyic acid on growth and developmemnt of in vitro-and ex vitro-derived 
lingonberry plants. Canadian J. of Plant Sci., 86(1): 235-243.

Fischer, D.L.D.O., Fachinello, J.C., Antunes, L.E.C., Tomaz, Z.F.P., Giacobbo, C.L., 2008a. Effect of indolebutryic acid and cultivar of hardwood cutting of blueberry. Revista Brasileira De Fruticultura, 30(2): 285-289.

Fischer, D.L.O., Fachinello, J.C., Antunes L.E.A.C., Timm, C.F., Giacobbo, C.L., 2008b. Rooting of semi-hardwood cuttings of blueberry under different indolebutryic acid concentrations. Rev. Bras. Frutic., Jaboticabal-SP, 30(2): 557-559.

Fischer, D.L.O., Fernades, G.W., Borges, E.A., Piana, C.F.B., Pasa, M.S., 2016. Rooting of blueberry hardwood cuttings treated with indolebutryic acid (IBA) and pro-rooting.Acta Horticulturae, 1117: 325-329.

Gough, B., 2008. An Encyclopedia of Small Fruit. CRC Press., 16-113p.

Grant, A. 2018. Growing cranberries from cuttings. Tips for rooting cranberry cuttings. https:/www.gardeningknowhow.com/edible/fruits/c ranberry/rooting-cranberry-cuttings.htm

Gustavson, B.A., 1999. Effect of collection time and environment on the rooting of lingonberry (Vaccinium vitis-idea L.) stem cuttings. Acta Agr. Scan. Section-B, Soil and Plant Sci., 49(4):242-247.

Gustavson, B.A., Stanys, V., 2000. Field performance of 'Sanna' lingonberry derived by micropropagation vs. stem cutting. Hortscience, 35(4): 742-744.

Hagidimitriou, M., Roper, T.R., 1994. Seasonal changes in nonstructural carbohydrates in Cranberry. J. Amer. Soc. Hort. Sci.: 119(5): 1029-1033. DOI: $10.21273 / \mathrm{JASHS}$.119.5.1029

Hartmann, H.T., Kester, D.E., Davies, F.T., Geneva, R.L., 2014. Hartmann \& Kester’s Plant Propagation : Principles and Practices.Pearson Publ., 927p.

Holloway, P., Zasada, J., 1979. Vegetative propagation of 11 common Alaska woody plants. Research Note, PNW-334, USDA, Forest Service. 12p.

Jamaieson, A.R., Nickerson, N.L., 2003. Field performance of the lowbush blueberry propagated by seed, stem cutting and micropropagation. Acta Horticulturae, 626: 423-428.

Karabulut, B., Çelik, H., 2019. Maviyemişin çoğaltılması, Türkiye ve dünyada yapılan çalışmalar. BAHÇE, 48 (Özel Say1-1): 197-206.

Kovr, K., Bakshi, P., Sharma, R.M., 2019. Cranberry. In: Cultivate Minor Temparete Fruits Scientifically (2 Prats) (Ed: Gosh, S.N.), Vol. 4: 128-181p. Narendra Publ. India.

Larson, B., Patten, K, Strik, B. 2002. Establishing The Cranberry Bed. In: Cranberry Production in the Pacific Northwest. A Pacific Northwest Ext. Publ. PNW247, 17-24p.

Lee, J.G., Lee, B.Y., 2009. Effect of rooting promotor and root zone temperature controls on growth and rooting of highbush blueberry cuttings. Korean J. of Hort. Scie and Tech., 27(1): 7-11.

Litwinczuk, W., Szczerba, G., Wrona, D., 2005. Field performance of highbush blueberries (Vaccinium corymbosum L.) cv 'Herbert' propagated by cutting and tissue culture. Scientia Hort. 106(2): 162-169. DOI: $10.1016 /$ j.scienta.2005.02.025

Magnitskiy, S., Ligarreto, M.G., Lancheros, H. O., 2011. Rooting of two type of cuttings of fruit crops Vaccinium floribundum Kunth and Disterigma alaternoides (Kunth) Niedenzu (Ericaceae)

Marangon, M.A., Biasi, L.A., 2013. Cutting propagation of blueberry in seasons of the year with indolebutryic acid and bottom heat. Pesg. Agropec. Bras., 48(1): 25-32. DOI: $10.1590 / S 0100-$ 204X2013000100004

Marcotrigiano, M., Mcglow S.P., 1991. A 2-stage micropropagation system for cranberries. J. of Amer. Soc. For Hort. Sci. 116(5): 911-916.

Marino, S.R., Williamson, J.G., Olmstead, J.W., 2014. Vegetative growth of three southern highbush blueberry cultivars obtained from micropropagation and softwood cuttings in two Florida locations. HortScience, 49(5): 556-561.

Martinussen, I., Nilsen, H., Rothe, G., Lund, L., Rapp, K., 2006. Seasonal variations in rooting of lingonberry (Vaccinium vitis-idea L.) cuttings. Acta Hort. 715: 439-442.

DOI: $10.17660 /$ ActaHortic.2006.715.66

Miller, S., Rawnsley, E., George, J., Patel, N., 2006. A comparison of blueberry propagation techniques used in New Zealand. Acta Horticulturae, 715: 397401. DOI: $10.17660 /$ ActaHortic.2006.715.59

Nascimento, D.C., Schuch, M.W., Peil, R.M.N., 2011. Rooting of blueberry microcuttings originated from semi-hidroponic clonal microgarden. Rev. Bras. Frutic., Jaboticabal-SP, 33(4): 1251-1256. http://dx.doi.org/10.1590/0100-29452019041

Nowakowska, K., Pacholczak, A., 2017. Analyses of genetic stability in the ex vitro rooted microcuttings of blueberry (Vaccinium corymbosum). Acta Scientiarum Polonorum-Hortorum Cultus, 16(5): 1927. DOI: $10.24326 /$ asphc.2017.5.3

Özgen, M., Çelik, H. 2007. Turnayemişi (Vaccinium macrocarpon Ait.) Yetiştiriciliği ve Ülkemiz İçin Potansiyeli. V. Ulusal Bahçe Bitkileri Kongresi, 4-7 Eylül, Erzurum. V. Ulusal Bahçe Bitkileri Kongresi, Cilt-1, Meyvecilik, 444-449s.

Pacholczak, A., Nowakowska, K., 2015. The ex vitro rooting of blueberry (Vaccinium corymbosum L.) microcuttings. Folia Hort., 27(2): 145-150. DOI: https://doi.org/10.1515/fhort-2015-0024

Parnaro, C., Macoline, S., Menegon, A., Richardson, M., 2017. WinRHIZO technology for measuring morphological traits of bermudagrass stolons. Agrononmy J., 109(6): 3007-3017.

Pelizza, T.R., Damiani, C.R., Rufato, A.R., Souza, A.L.K., Ribeiro, M.F., Schuch, MW., 2011. 
Microcutting in blueberry using brach from different posistions and substrates. Bragantia, Campinas, 70(2): 319-314.

Ristow, N.C., Antunes, L.E.C., Carpenedo, S., 2012. Substrates for rooting microcutting blueberry cultivar Georgiagem. Rev. Bras. Frutic., JaboticabalSP, 34(1): 262-268. DOI: $10.1590 /$ S010029452012000100035

Roper, T.R., 1995. Cranberry production in Wisconsin. Univ. of Wisconsin, Ext. Serv. 8p.

Roper, T.R., Vorsa, N., 1997. Cranberry : Botany and Horticulture. In Horticultural Reviews (Edt: J. Janick.): 21:215-247.

Ruter, J.M., 2015. Cloning Plants by Rooting Stem Cuttings. In : Plant Propagation Concepts and Laboratory Exercises (Ed. Caula A. Beyl and Robert N. Trigiano). CRC Press, 219-229p.

Scorza R., Welker W.V. 1988. Cranberries (Vaccinium macrocarpon Ait.). In: Bajaj Y.P.S. (eds) Crops II. Biotechnology in Agriculture and Forestry, Springer, Berlin, Heidelberg 6: 199-208.

St. Pierre, R.G. 1996. The Lingonberry. Saskatoon, Saskatchewan, Canada: Department of Horticulture Science, University of Saskatchewan-Saskatoon.

Strik, B., Davenport, J. 2002. Botonical and Physiological Characterstics. In:Cranberry Production in The Pasific in Northwest. A Pacific Northwest Ext. Publ. PNW247, 5-10p.

Strik, B., Larson, B., Patten, K., 2002. The Cranberry Industry. In: Cranberry Production in the Pacific Northwest. A Pacific Northwest Ext. Publ. PNW247, 1-4p.

Strik, B., Poole, A. 2002. Maintaining the Bed Pruning. In: Cranberry Production in the Pacific Northwest. A Pacific Northwest Ext. Publ. PNW247, 49-50p.

Szwonek, E., Kozinski, B., Smolarz, K., Bryk, H., SasPaszt, L., Derkowska, E., Estabrooks, E., 2016. Cranberry (Vaccinium macrocarpon Ait.) growth characteristics versus different soil pecularities. Acta Horticulturae, 1117: 157-161.

Şenyaşa, F.N., Çelik, H., 2019. Turnayemişinin özellikleri, yetiştiriciliği, iklim ve toprak istekleri ile sağlık açısından yararları. Bahçe, 48 (Özel Sayı-1): 237-246.

Trehane, J. 2004. Blueberries, Cranberries and Other Vacciniums. Timber Press, Portland, Cambridge, 2973p.

Varshney, A., Anis, M., 2014. Trees: Propagation and Concervation. Springer, 1-35p.

Welker, W.V., Vass, G.D., 1983. Influence of size and orientation of cranberry cuttings upon plant development. Hortscience, 18(5): 722-723. 